\title{
Patrinia scabiosaefolia induces mitochondrial-dependent apoptosis in a mouse model of colorectal cancer
}

\author{
LIYA LIU $^{1,2^{*}}$, ALING SHEN $^{1,2^{*}}$, YOUQIN CHEN $^{3}$, LIHUI WEI $^{1,2}$, JIUMAO LIN $^{1,2}$, \\ THOMAS J. SFERRA ${ }^{3}$, ZHENFENG HONG ${ }^{1,2}$ and JUN PENG ${ }^{1,2}$ \\ ${ }^{1}$ Academy of Integrative Medicine and ${ }^{2}$ Fujian Key Laboratory of Integrative Medicine on Geriatrics, \\ Fujian University of Traditional Chinese Medicine, Minhou Shangjie, Fuzhou, Fujian 350122, P.R. China \\ ${ }^{3}$ Rainbow Babies and Children's Hospital, Case Western Reserve University School of Medicine, Cleveland, OH 44106, USA
}

Received March 22, 2013; Accepted May 17, 2013

DOI: $10.3892 /$ or.2013.2528

\begin{abstract}
Disrupted apoptosis not only confers a survival advantage to cancer cells but also causes resistance to chemotherapies. Therefore, inducing cell apoptosis has become a promising strategy for anticancer treatment. Patrinia scabiosaefolia (PS) has long been used to clinically treat various types of malignancies including colorectal cancer (CRC). However, the precise mechanism of its tumoricidal activity remains largely unclear. Using a CRC mouse xenograft model and a human colon carcinoma cell line, HT-29, in the present study, we evaluated the antitumor activities of an ethanol extract of Patrinia scabiosaefolia (EEPS), and investigated the underlying molecular mechanisms. We found that EEPS inhibited CRC growth both in vivo and in vitro, without apparent adverse side-effects. Moreover, EEPS treatment promoted apoptosis in CRC tumor tissues and in HT-29 cells, suggesting that the inhibitory effect of EEPS on tumor growth was due to its pro-apoptotic activity. Furthermore, EEPS treatment inhibited the expression of anti-apoptotic Bcl-2 but enhanced pro-apoptotic Bax expression at both transcriptional and translational levels. Finally, EEPS induced the loss of mitochondrial membrane potential and activation of caspase- 9 and -3 in HT-29 cells. Taken together, data in this study suggest
\end{abstract}

Correspondence to: Dr Jun Peng, Fujian Key Laboratory of Integrative Medicine on Geriatrics, Fujian University of Traditional Chinese Medicine, 1 Huatuo Road, Minhou Shangjie, Fuzhou, Fujian 350122, P.R. China

E-mail: pjunlab@hotmail.com

${ }^{*}$ Contributed equally

Abbreviations: CRC, colorectal cancer; TCM, Traditional Chinese Medicine; EEPS, ethanol extract of Patrinia scabiosaefolia; TUNEL, TdT-mediated dUTP nick end labeling; IHS, immunohistochemical staining

Key words: Patrinia scabiosaefolia, herbal medicine, anticancer treatment, apoptosis, mitochondrion that induction of cancer cell apoptosis via the mitochondrialdependent pathway may be one of the mechanisms whereby PS exerts anticancer activity.

\section{Introduction}

Apoptosis is essential for tissue homeostasis by eliminating excess or damaged cells. Deregulation of this vital biological process contributes to various diseases including cancer $(1,2)$. The mitochondrion plays an important role in the process of apoptosis $(3,4)$, which is tightly regulated by Bcl-2 family proteins including both anti-apoptotic members such as Bcl-2 and pro-apoptotic members such as Bax. One possible mechanism whereby $\mathrm{Bcl}-2$ family proteins regulate apoptosis is through their effect on the permeability of the mitochondrial outer membrane (MOM) via homo- or hetero-association (5). Activation of pro-apoptotic Bax induces mitochondrial outer membrane permeabilization (MOMP), leading to the release of pro-apoptotic proteins such as cytochrome $c$ from mitochondria to the cytosol, which in turn triggers the activation of the caspase cascade and eventually cell death (6-9). The antiapoptotic Bcl-2 protects cells from apoptosis by interacting with Bax and inhibiting Bax-mediated MOMP (10-13). Thus, the ratio of active anti- and pro-apoptotic Bcl-2 family proteins determines the fate of cells; and alteration of this ratio impairs the normal cellular apoptotic program which is associated with the pathogenesis of various diseases including cancer $(14,15)$. It has been shown that Bcl-2 is commonly overexpressed in many types of cancer (16), which not only confers a survival advantage to cancer cells but also causes resistance to conventional chemotherapies and radiotherapies. Therefore, inducing cell apoptosis via modulating Bcl-2 family expression is a promising approach for anticancer therapies.

Natural products, including Traditional Chinese Medicines (TCM), have been considered as alternative cancer remedies for many years since they have relatively fewer adverse effects as compared to modern chemotherapeutics $(17,18)$. Patrinia scabiosaefolia (PS) is a perennial plant natively distributed in Eastern Asia. As a well-known Oriental folk medicine, PS has long been used in China for the treatment of edema, appendicitis, endometritis and other inflammatory illnesses (19). PS is also used as a major component in several TCM formulas 
to clinically treat gastrointestinal cancer (20). However, the precise mechanism of its antitumor activity remains largely unknown. Using a CRC mouse xenograft model and a human colon carcinoma cell line, in this study, we evaluated the therapeutic efficacy of PS against tumor growth both in vivo and in vitro, and investigated the underlying molecular mechanisms.

\section{Materials and methods}

Materials and reagents. Dulbecco's modified Eagle's medium (DMEM), fetal bovine serum (FBS), penicillin-streptomycin, trypsin-EDTA, TRIzol reagent, JC-1, caspase-3 and -9 colorimetric protease assay kits were purchased from Life Technologies (Carlsbad, CA, USA). SuperScript II Reverse Transcriptase was obtained from Promega Corporation (Madison, WI, USA). Bcl-2 and Bax antibodies, and horseradish peroxidase (HRP)-conjugated secondary antibodies were obtained from Cell Signaling Technology, Inc. (Beverly, MA, USA). TUNEL assay kit was purchased from R\&D Systems (Minneapolis, MN, USA). Hoechst staining kit was obtained from Beyotime Institute of Biotechnology (Jiangsu, China). All other chemicals, unless otherwise stated, were obtained from Sigma-Aldrich (St. Louis, MO, USA).

Preparation of an ethanol extract from Patrinia scabiosaefolia (EEPS). EEPS was prepared as described previously (21). For animal experiments, EEPS powder was dissolved in saline to a working concentration of $250 \mathrm{mg} / \mathrm{ml}$. In cell-based experiments EEPS powder was dissolved in $50 \%$ dimethyl sulfoxide (DMSO) to a stock concentration of $250 \mathrm{mg} / \mathrm{ml}$, and the working concentrations of EEPS were made by diluting the stock solution in the culture medium. The final concentration of DMSO in the medium for all cell experiments was $<0.5 \%$.

Cell culture. Human colon carcinoma HT-29 cells were obtained from the cell bank of the Chinese Academy of Science (Shanghai, China). The cells were grown in DMEM containing $10 \%$ (v/v) FBS, $100 \mathrm{U} / \mathrm{ml}$ penicillin and $100 \mu \mathrm{g} /$ $\mathrm{ml}$ streptomycin. Cells were cultured at $37^{\circ} \mathrm{C}$ in a humidified incubator with $5 \% \mathrm{CO}_{2}$.

Animals. Male BALB/c athymic (nude) mice (with an initial body weight of 20-22 g) were obtained from Shanghai SLAC Laboratory Animal Co., Ltd. (Shanghai, China) and housed under pathogen-free conditions with controlled temperature $\left(22^{\circ} \mathrm{C}\right)$, humidity and a 12 -h light/dark cycle. Food and water were given ad libitum throughout the experiment. All animal treatments were strictly in accordance with international ethical guidelines and the National Institutes of Health Guide concerning the Care and Use of Laboratory Animals, and the experiments were approved by the Institutional Animal Care and Use Committee of Fujian University of Traditional Chinese Medicine.

In vivo tumor xenograft study. HT-29 $\left(1.5 \times 10^{6}\right)$ cells mixed with Matrigel (1:1) were subcutaneously injected in the right flank to initiate tumor growth. After 5 days of xenograft implantation, mice were randomly divided into 2 groups $(\mathrm{n}=6)$ and given gavage-feeding with $1.93 \mathrm{~g} / \mathrm{kg} / \mathrm{day}$ of EEPS or saline daily, 5 days a week for 21 days. Body weight was recorded every 2 days throughout the study. At the end of the experiment, tumors were excised and weighed, and part of the tumor was fixed in buffered formalin and the remaining part was stored at $-80^{\circ} \mathrm{C}$.

Detection of apoptosis by TUNEL. The sections $(4-\mu \mathrm{m})$ of tumor samples were analyzed by TUNEL staining using TumorTACS In Situ Apoptosis kit. Apoptotic cells were counted as DAB-positive cells (brown stained) in 5 arbitrarily selected microscopic fields at a magnification of $\mathrm{x} 400$. TUNEL-positive cells were expressed as a percentage of the total cells.

Evaluation of cell viability by MTT assay. Viability of HT-29 cells was examined by the 3-(4,5-dimethylthiazol-2-yl)-2, 5-diphenyltetrazolium bromide (MTT) colorimetric assay. HT-29 cells were seeded into 96-well plates at a density of $1 \times 10^{4}$ cells/well in $0.1 \mathrm{ml}$ medium. The cells were treated with various concentrations of EEPS for 24, 48 and $72 \mathrm{~h}$ respectively. At the end of the treatment, $100 \mu \mathrm{l}$ MTT $[0.5 \mathrm{mg} / \mathrm{ml}$ in phosphate-buffered saline (PBS)] was added to each well, and the samples were incubated for an additional $4 \mathrm{~h}$ at $37^{\circ} \mathrm{C}$. The purple-blue MTT formazan precipitate was dissolved in $100 \mu 1$ DMSO. The absorbance was measured at $570 \mathrm{~nm}$ using an ELISA reader (Model ELX800; BioTek Instruments Inc., Winooski, VT, USA).

Observation of morphologic changes. HT-29 cells were seeded into 6 -well plates at a density of $2.0 \times 10^{5}$ cells/well in $2 \mathrm{ml}$ medium. The cells were treated with the indicated concentrations of EEPS for $24 \mathrm{~h}$. Cell morphology was observed using a phase-contrast microscope (Leica, Mannheim, Germany). The images were captured at a magnification of $\times 200$.

Detection of apoptosis with Hoechst staining. HT-29 cells were seeded into 12 -well plates at a density of $1 \times 10^{5}$ cells/ well in $1 \mathrm{ml}$ medium. After the treatment of EEPS for $24 \mathrm{~h}$, cell apoptosis was determined by the Hoechst staining kit according to the manufacturer's instruction. Briefly, at the end of the treatment, cells were fixed with $4 \%$ polyoxymethylene and then incubated in Hoechst solution for 5-10 min in the dark. The staining images were recorded using a phasecontrast fluorescence microscope (Leica). The images were captured at a magnification of x400.

Measurement of mitochondrial membrane potential ( $\Delta \Psi m)$ by flow cytometry. JC- 1 is a cationic dye that exhibits potential-dependent accumulation in mitochondria, indicated by a fluorescence emission shift from green to red, which can be used as an indicator of mitochondrial potential. In this experiment, $1 \times 10^{6}$ treated HT-29 cells were resuspended after trypsinization in $1 \mathrm{ml}$ of medium and incubated with $10 \mu \mathrm{g} / \mathrm{ml}$ of $\mathrm{JC}-1$ at $37^{\circ} \mathrm{C}$ in $5 \% \mathrm{CO}_{2}$, for $30 \mathrm{~min}$. Both red and green fluorescence emissions were analyzed by flow cytometry after JC-1 staining.

Analysis of caspase activation. The activity of caspase-9 and -3 was determined by a colorimetric assay kit following 
A
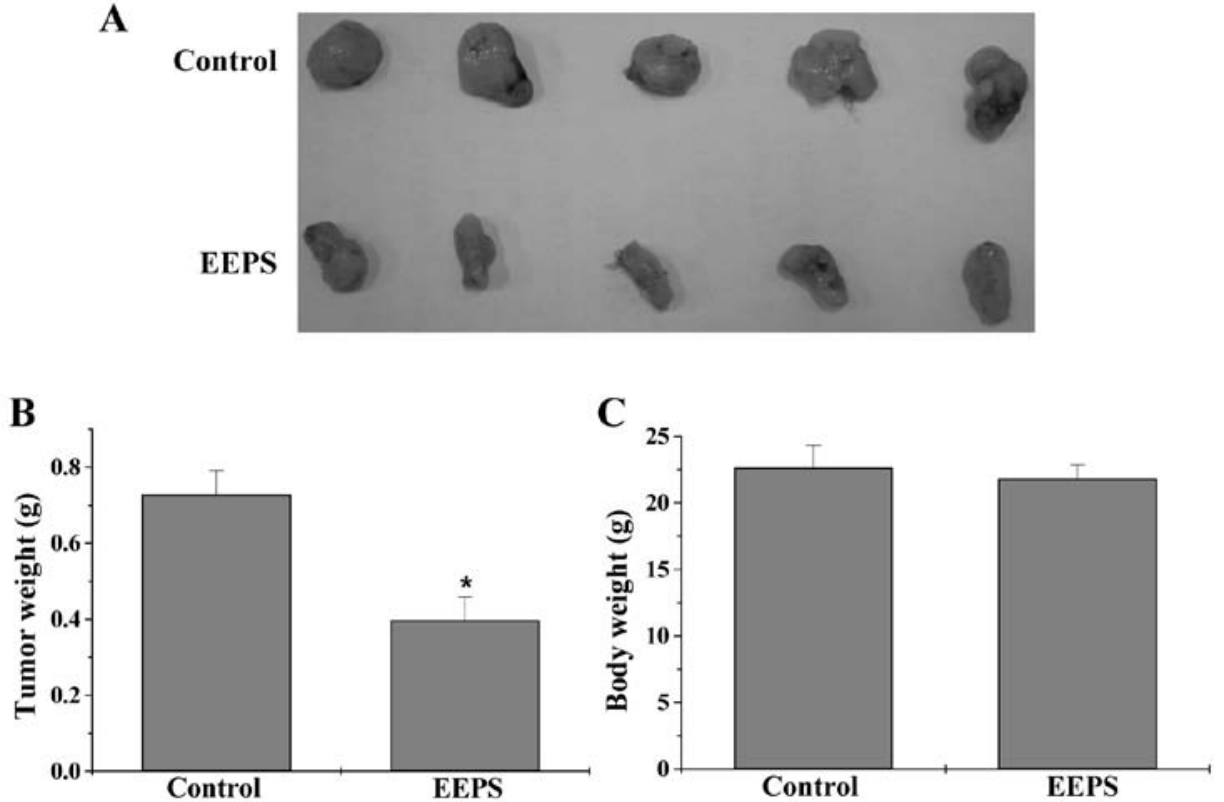

Figure 1. Effect of an ethanol extract of Patrinia scabiosaefolia (EEPS) on tumor growth in colorectal cancer (CRC) xenograft nude mice. After tumor development, the mice received an intra-gastric administration of a $1.93 \mathrm{~g} / \mathrm{kg} / \mathrm{day}$ dose of EEPS or saline daily, 5 days a week for 21 days. At the end of the experiment, the animals were sacrificed and the tumors were removed and weighed. (A) Representative images of tumors from the control and EEPS-treated mice. (B) Tumor weight. (C) Body weight. Data shown are averages with the SD (error bars) from 6 individual mice in each group. "P<0.05, vs. controls.

the manufacturer's instructions. Briefly, after treatment with various concentrations of EEPS for $24 \mathrm{~h}, \mathrm{HT}-29$ cells were lysed with lysis buffer for $30 \mathrm{~min}$ on ice. The lysed cells were centrifuged at 14,000 $\mathrm{x}$ g for $10 \mathrm{~min}$, and $100 \mu \mathrm{g}$ of the protein was incubated with $50 \mu \mathrm{l}$ of Asp-Glue-Val-Asp (DEAD)-pNA (specific substrate of caspase-3) or Leu-Glu-His-Asp (LEHD)-pNA (specific substrate of caspase-9) at $37^{\circ} \mathrm{C}$ in the dark for $2 \mathrm{~h}$. Samples were read at $405 \mathrm{~nm}$ in an ELISA plate reader. The data were normalized to the caspase activity in control cells and represented as 'fold of control'.

RNA extraction and RT-PCR analysis. HT-29 cells were seeded into 6 -well plates at a density of $2.0 \times 10^{5}$ cells/well in $2 \mathrm{ml}$ medium. The cells were treated with indicated concentrations of EEPS for $24 \mathrm{~h}$. Total RNA was isolated with TRIzol reagent. Oligo(dT)-primed RNA $(1 \mu \mathrm{g})$ was reverse-transcribed with SuperScript II Reverse Transcriptase according to the manufacturer's instructions. The obtained cDNA was used to determine the mRNA amount of Bcl-2 and Bax by PCR. GAPDH was used as an internal control. The sequences of the primers used for amplification of Bcl-2, Bax and GAPDH transcripts are as follows: Bcl-2 forward, 5'-CAGCTGCACCT GACGCCCTT-3 and reverse, 5'-GCCTCCGTTATCCTGGAT CC-3'; Bax forward, 5'-TGCTTCAGGGTTTCATCCAGG-3' and reverse, 5'-TGGCAAAGTAGAAAAGGGCGA-3'; GAPDH forward, 5'-GTCATCCATGACAACTTTGG-3' and reverse, 5'-GAGCTTGACAAAGTGGTCGT-3'.

Western blot analysis. HT-29 $\left(1 \times 10^{6}\right)$ cells were seeded into culture flasks in $5 \mathrm{ml}$ medium and treated with various concentrations of EEPS for $24 \mathrm{~h}$. The treated cells were lysed with mammalian cell lysis buffer containing protease and phosphatase inhibitor cocktails, and the lysates were separated by $12 \%$ SDS-PAGE gels using $80 \mathrm{~V}$ for $2 \mathrm{~h}$. The proteins were then electrophoretically transferred onto PVDF membranes. Membranes were blocked for $2 \mathrm{~h}$ with blocking solution at room temperature, washed in TBS with $0.25 \%$ Tween-20 (TBS-T) and exposed to primary antibodies against Bcl-2 and Bax $(1: 1,000)$ overnight at $4^{\circ} \mathrm{C}$. $\beta$-actin $(1: 1,000)$ was measured as an internal control for protein loading. After the membranes were washed in TBS-T, secondary HRP-conjugated antibodies (anti-rabbit or anti-mouse) were added at 1:2,000 dilutions for $1 \mathrm{~h}$ at room temperature and the membranes were washed again in TBS-T followed by enhanced chemiluminescence detection.

Statistical analysis. Data are presented as means \pm SD for the indicated number of independently performed experiments and analyzed using the SPSS package for Windows (version 16.0). Statistical analysis of the data was performed with the Student's t-test and ANOVA. Differences with $\mathrm{P}<0.05$ were considered to be statistically significant.

\section{Results}

EEPS inhibits colorectal cancer (CRC) growth in vivo and in vitro. The anticancer activity of EEPS in vivo was determined via examining tumor weight in CRC xenograft mice, whereas its side-effects were determined by measuring body weight changes. As shown in Fig. 1A and B, EEPS treatment caused a $45 \%$ decrease in tumor weight compared with the control $(0.728 \pm 0.064$ or $0.397 \pm 0.062 \mathrm{~g} /$ mouse in control or EEPS-treated group, $\mathrm{P}<0.05)$, whereas EEPS did not affect body weight in the experimental animals (Fig. 1C). To determine the in vitro inhibitory effects of EEPS on the growth of CRC cells, we examined the viability of human colon carcinoma HT-29 cells using the MTT assay. As shown in Fig. 2, EEPS treatment reduced HT-29 cell viability in both 


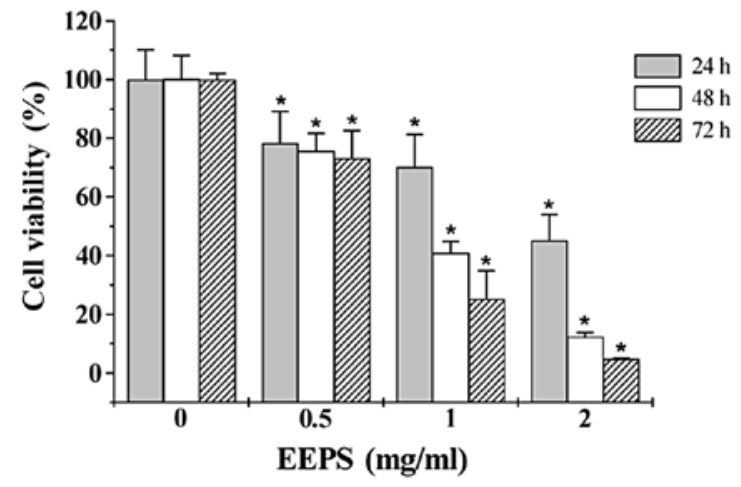

Figure 2. Effect of an ethanol extract of Patrinia scabiosaefolia (EEPS) on the viability of HT-29 cells. Cell viability was determined by the MTT assay after HT-29 cells were treated with various concentrations of EEPS for 24 , 48 or $72 \mathrm{~h}$. The data were normalized to the viability of control cells (100\%). Data are the averages with SD (error bars) from 3 independent experiments. ${ }^{*} \mathrm{P}<0.05$, vs. control cells.

a dose- and time-dependent manners $(\mathrm{P}<0.05)$. We further verified these results by determining the effect of EEPS on HT-29 cell morphology that represents the healthy status of cells in culture. As shown in Fig. 3, untreated HT-29 cells appeared as densely packed and disorganized multilayers, whereas after incubation with various concentrations of EEPS for $24 \mathrm{~h}$ many of the cells became rounded and shrunken, and detached from each other or floated in the medium. Taken together, this suggests that EEPS is effective in suppressing colorectal tumor growth both in vivo and in vitro, without apparent adverse effects.

EEPS induces cancer cell apoptosis via increasing the proapoptotic Bax/Bcl-2 ratio. Cell apoptosis in CRC tumor tissues was determined by immunohistochemical (IHC) staining for TUNEL. As shown in Fig. 4A, the percentage of TUNEL-positive cells in the control and the EEPS-treated mouse group was $37.00 \pm 16.70$ and $84.33 \pm 23.25 \%$, respectively, indicating the pro-apoptotic effect of EEPS in vivo. The apoptosis of HT-29 cells was evaluated by observation of nuclear morphological changes by cell nuclear staining with DNA-binding dye Hoechst. As shown in Fig. 4B, EEPS-treated cells showed condensed chromatin and fragmented nuclear morphology, typical apoptotic morphological features, whereas the untreated cell nuclei were homogeneously stained and less intense.

To explore the mechanism of the pro-apoptotic activity of EEPS, we examined its effect on the expression of Bcl-2 family proteins that are important regulators of apoptosis. As shown in Fig. 5A and C, EEPS significantly reduced the anti-apoptotic Bcl-2 mRNA level both in HT-29 cells and the CRC tumor tissues, whereas that of pro-apoptotic Bax was profoundly increased after EEPS treatment. The protein expression patterns of $\mathrm{Bcl}-2$ and $\mathrm{Bax}$ were similar to their respective mRNA levels (Fig. 5B and D), suggesting that EEPS promotes CRC cell apoptosis both in vivo and in vitro through an increase in the pro-apoptotic $\mathrm{Bax} / \mathrm{Bcl}-2$ ratio.

EEPS induces the loss of mitochondrial potential $(\Delta \Psi m)$ and the activation of caspase-3 and -9 in HT-29 cells. The effect of EEPS on the change in mitochondrial membrane potential in HT-29 cells was examined via JC-1 staining followed by FACS analysis. The membrane-permeable JC-1 dye displays potential-dependent accumulation in mitochondria, indicated by a fluorescence emission shift from green $(\sim 525 \mathrm{~nm})$ to red $(\sim 590 \mathrm{~nm})$. Therefore, collapse of mitochondrial potential during apoptosis is indicated by a decrease in the ratio of red/green fluorescence intensity. As shown in Fig. 6, after treatment with $0,0.5,1$ and $2 \mathrm{mg} / \mathrm{ml}$ of EEPS the JC-1 red/green fluorescent ratio in HT-29 cells was $5.34 \pm 0.84,3.12 \pm 0.75$,
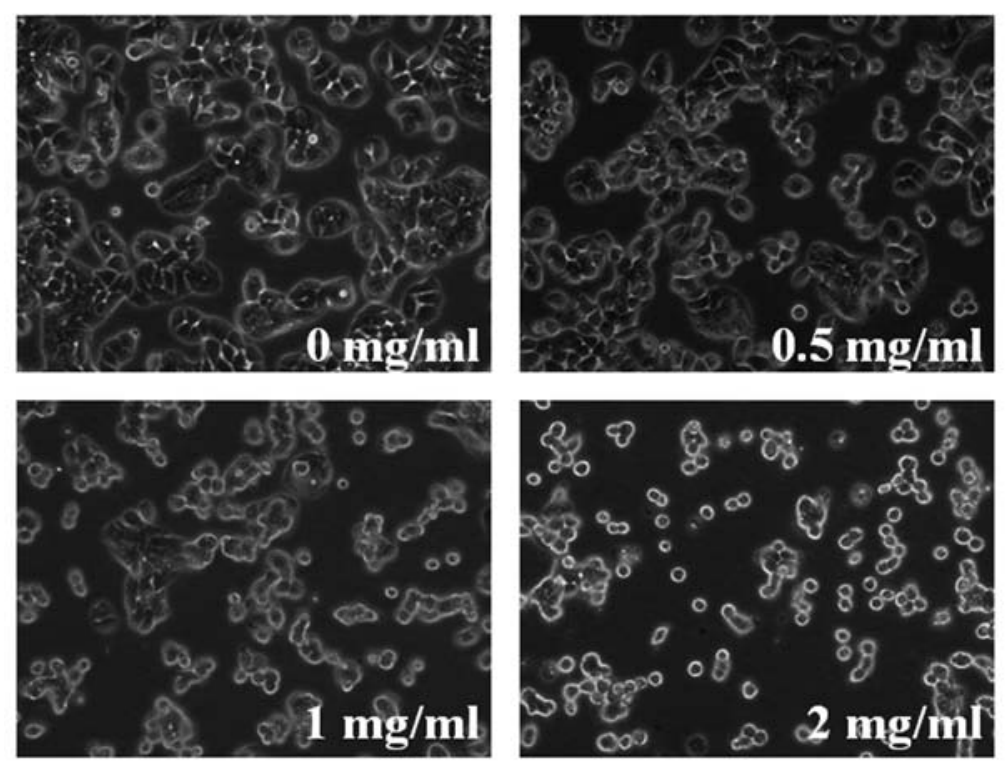

Figure 3. Effect of an ethanol extract of Patrinia scabiosaefolia (EEPS) on the morphology of HT-29 cells. The HT-29 cells were treated with the indicated concentrations of EEPS for $24 \mathrm{~h}$ and morphological changes were observed using phase-contrast microscopy. The images were captured at a magnification of $\mathrm{x} 200$. Images are representative of 3 independent experiments. 
A

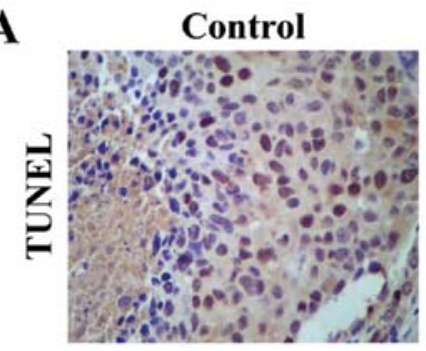

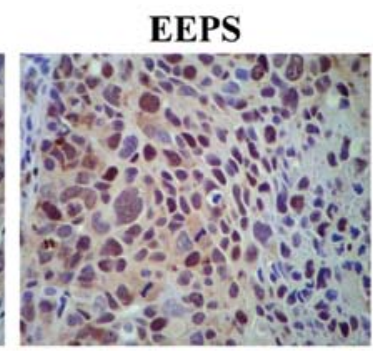
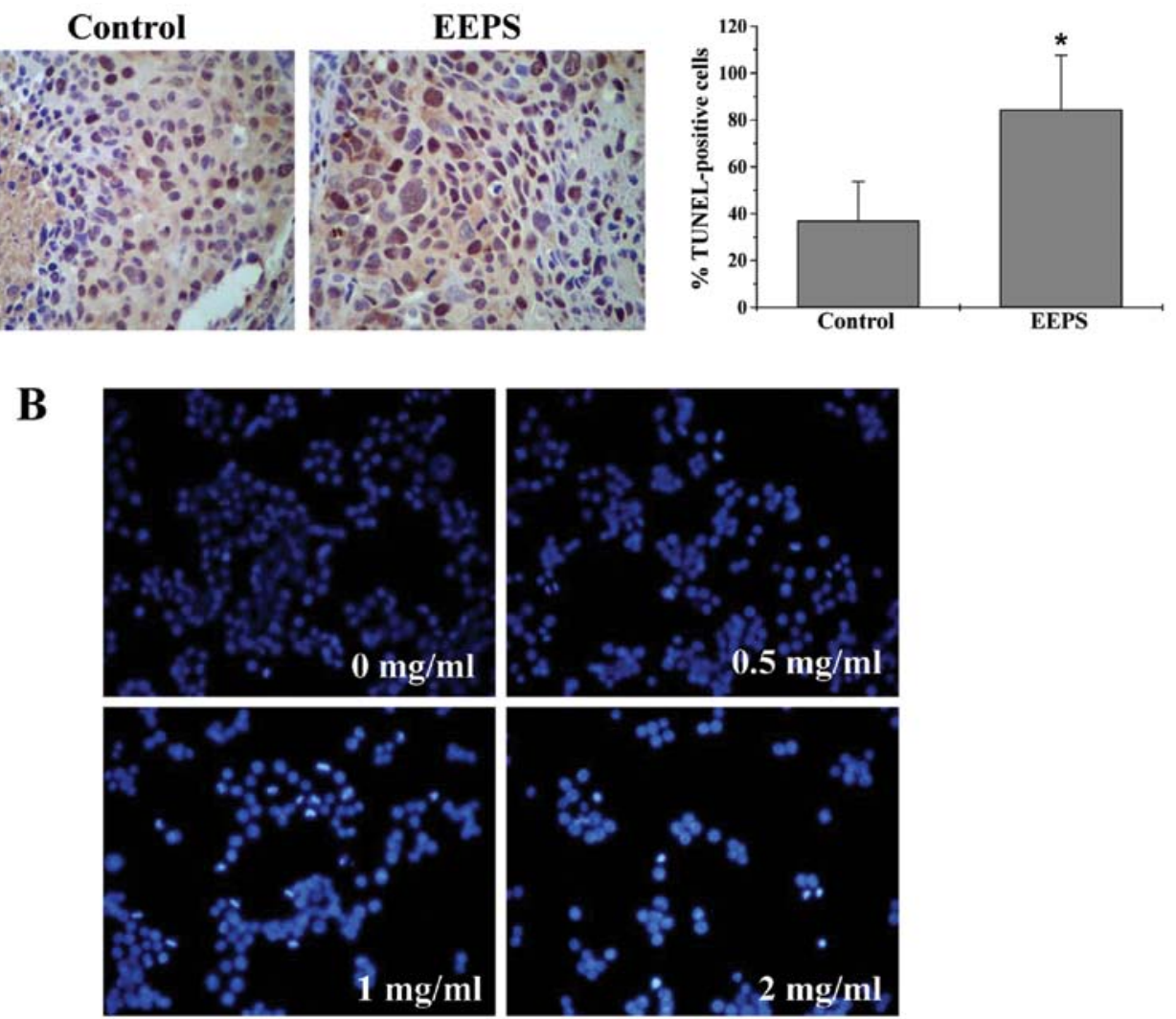

Figure 4. Effect of an ethanol extract of Patrinia scabiosaefolia (EEPS) on apoptosis in colorectal cancer (CRC) xenograft mouse tissues and HT-29 cells. (A) At the end of the experiment, tumor tissues were processed for immunohistochemical staining (IHS) for TUNEL. The images are representative ones taken at a magnification of x400. Quantification of IHS assay was represented as the percentage of positively stained cells. Data shown are averages with SD (error bars) from 6 individual mice in each group. ${ }^{*} \mathrm{P}<0.05$, vs. controls. (B) HT-29 cells were treated with the indicated concentrations of EEPS for $24 \mathrm{~h}$ and stained with Hoechst. The staining images were recorded using a phase-contrast fluorescence microscope. The images were captured at a magnification of $\mathrm{x}$ 400. Images are representative of 3 independent experiments.

A

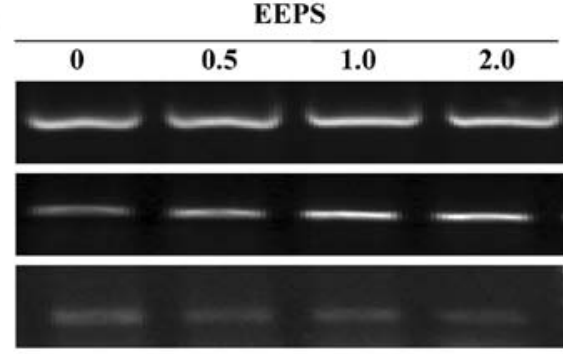

B

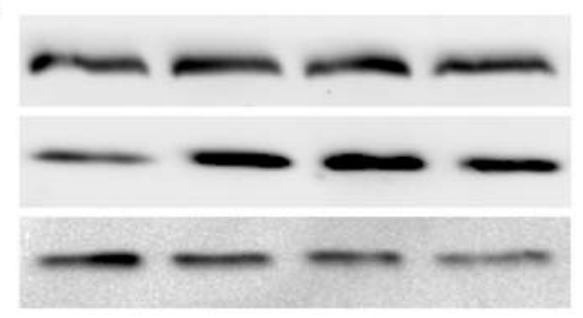

C

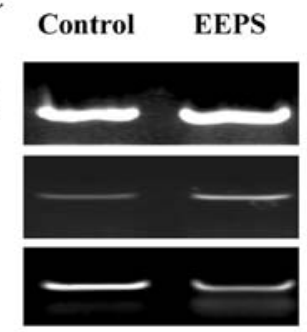

D

$\beta$-actin

Bax

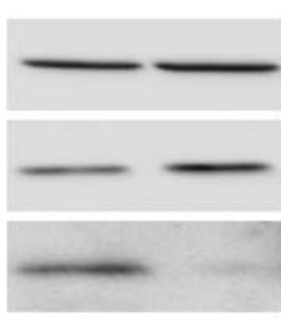

Figure 5. Effect of an ethanol extract of Patrinia scabiosaefolia (EEPS) on the expression of Bax and Bcl-2 in colorectal cancer (CRC) xenograft mouse tissues and HT-29 cells. (A and C) The mRNA levels of Bcl-2 and Bax in HT-29 cells and CRC xenograft mouse tissues were determined by RT-PCR. (B and D) The protein expression of Bcl-2 and Bax was determined by western blot analysis. GAPDH and $\beta$-actin were used as the internal controls for the RT-PCR or western blotting, respectively. Images are representative from 6 individual mice in each group or from 3 independent cell-based experiments.

$2.93 \pm 0.41,1.69 \pm 0.30(\mathrm{P}<0.05)$ respectively, suggesting that EEPS dose-dependently induced the loss of mitochondrial membrane potential in the CRC cells.
To identify the downstream effectors in the apoptotic signaling pathway, the activation of caspase- 3 and -9 was examined by a colorimetric assay using specific chromophores, 

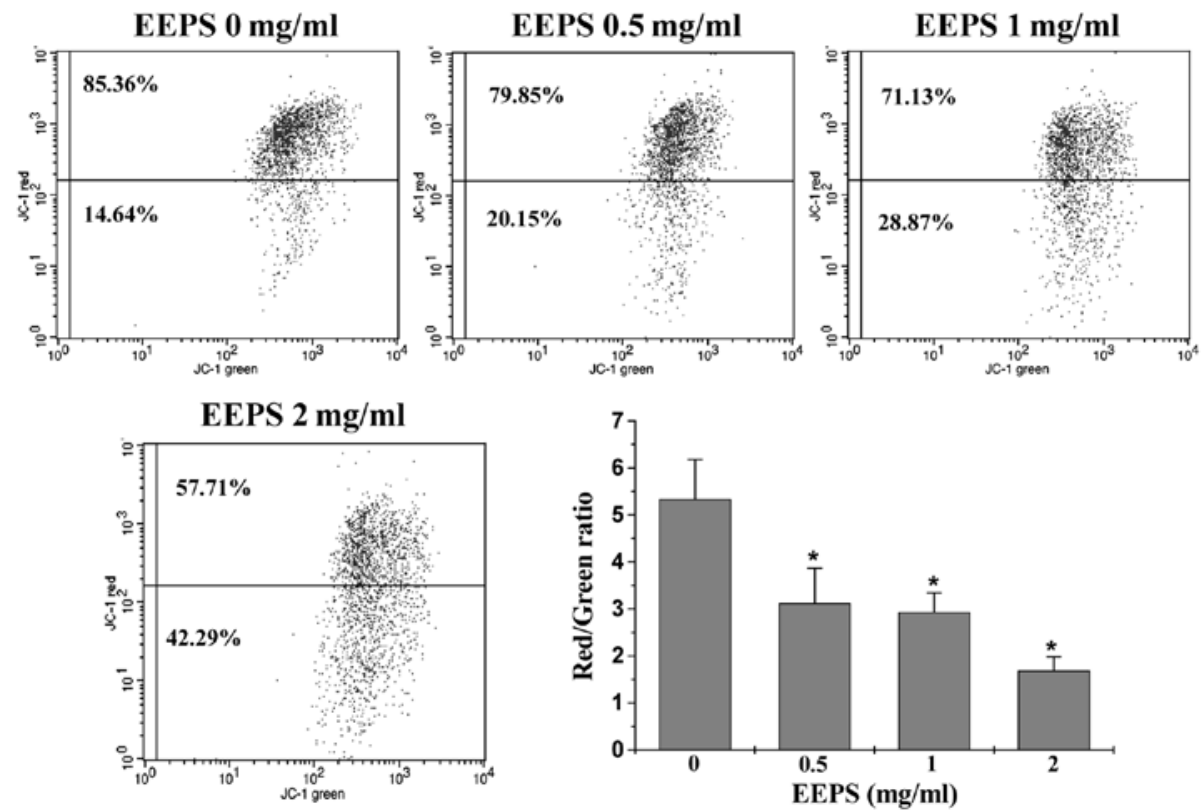

Figure 6. Effect of an ethanol extract of Patrinia scabiosaefolia (EEPS) on the loss of mitochondrial membrane potential in HT-29 cells. Cells were treated with the indicated concentrations of EEPS for $24 \mathrm{~h}$ and stained with JC-1. The mean JC-1 fluorescence intensity was detected using FACS analysis. Images are representative of 3 independent experiments. Data shown are averages with SD (error bars) from 3 independent experiments. " $\mathrm{P}<0.05$, vs. control cells.
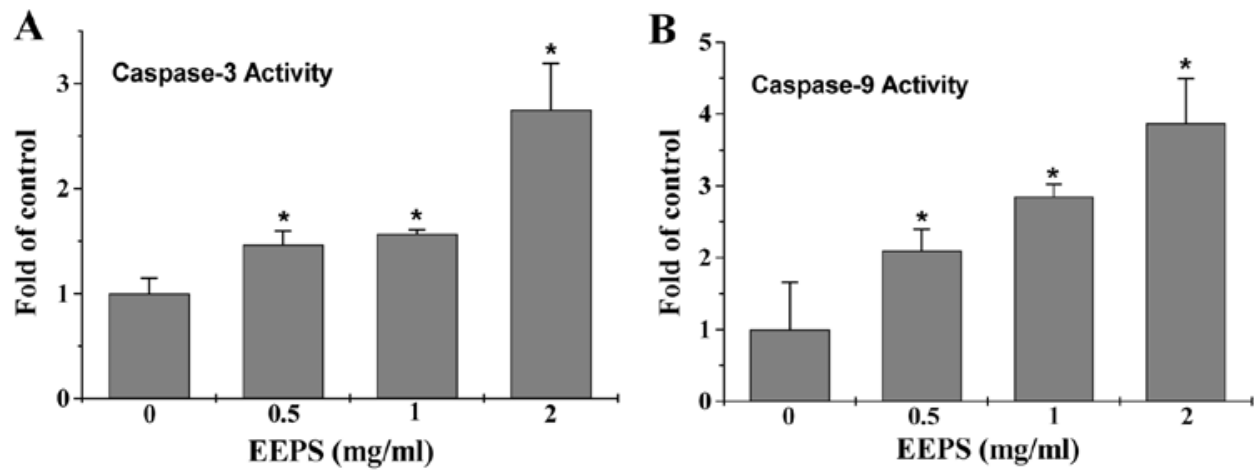

Figure 7. Effect of an ethanol extract of Patrinia scabiosaefolia (EEPS) on the activity of caspases in HT-29 cells. The cells were treated with the indicated concentrations of EEPS for $24 \mathrm{~h}$. (A) Caspase-3 and (B) caspase- 9 activity was determined by a colorimetric assay. The data were normalized to the caspase activities of the control cells and represented as 'fold of control'. Data are averages with SD (error bars) from 3 independent experiments. "P<0.05, vs. control cells.

DEVD-pNA (specific substrate of caspase-3) and LEHD-pNA (specific substrate of caspase-9). As showed in Fig. 7, EEPS treatment significantly and dose-dependently induced activation of both caspase-3 and -9 in HT-29 cells $(\mathrm{P}<0.05)$.

\section{Discussion}

Colorectal carcinoma (CRC) is the most common human malignancy with over one million new cases and half a million deaths worldwide each year (22). Chemotherapy is the main therapeutic approach for invasive and metastatic CRC (23). However, due to drug resistance and an unacceptable level of toxicity, the overall patient response to currently used anticancer chemotherapies is less than $40 \%$ (24-26). These problems highlight the urgent need for the development of novel cancer chemotherapies. Natural products, including Traditional Chinese Medicines (TCM), have been the subject of recent interest as anticancer agents, as they have relatively few side-effects and have been used as alternative remedies for a variety of diseases, including cancer. Patrinia scabiosaefolia (PS), an important traditional Chinese herbal medicine, has many reported pharmacological applications, including anticancer activity (21). However, the mode of its antitumor action is largely unknown. Therefore, before PS can be developed as an anticancer agent, the molecular mechanism of its anticancer activity should be fully elucidated.

Using a CRC mouse xenograft model and a human colon carcinoma cell line, here for the first time we demonstrated that EEPS inhibited cancer growth both in vivo and in vitro, without apparent toxicity. In addition, by using TUNEL and Hoechst staining, we found that EEPS promoted apoptosis in tumors of CRC mice and in colon cancer cells. The mitochondrial-dependent pathway is the most common apoptotic pathway in vertebrate animal cells. A key commitment step 
in the induction of cellular apoptosis through the mitochondrial-dependent pathway is mitochondrial outer membrane permeabilization (MOMP) $(27,28)$, which is the point of convergence for a large variety of intracellular apoptotic signaling pathways leading to the release of many apoptogenic proteins from the mitochondrial intermembrane space. During the process of MOMP, the electrochemical gradient across the mitochondrial membrane collapses resulting in the loss of mitochondrial membrane potential. Our data here clearly showed that treatment with EEPS induces a collapse of mitochondrial membrane potential.

Caspases, represented by a family of cysteine proteases, are important factors modulating the apoptotic response. Caspase-3 is a key executioner of apoptosis, which is activated by an initiator caspase such as caspase-9 during mitochondrial-mediated apoptosis. In this study, we found that EEPS dose-dependently induced the activation of both caspase- 9 and -3 in HT-29 cells. Mitochondrial-dependent apoptosis is highly regulated by Bcl-2 family proteins. MOMP is thought to occur through the formation of pores in mitochondria by pro-apoptotic Bax-like proteins, which can be inhibited by anti-apoptotic Bcl-2-like members. The ratio of Bax to Bcl-2 thus is critical for determining the fate of cells. Consistent with its pro-apoptotic activity, EEPS treatment increased the pro-apoptotic $\mathrm{Bax} / \mathrm{Bcl}-2$ ratio both in $\mathrm{CRC}$ tumors and in HT-29 cells.

\section{Acknowledgements}

This study was sponsored by the National Natural Science Foundation of China (81073097) and the Developmental Fund of Chen Keji Integrative Medicine (CKJ 2011001).

\section{References}

1. Adams JM and Cory S: The Bcl-2 apoptotic switch in cancer development and therapy. Oncogene 26: 1324-1337, 2007.

2. Cory S and Adams JM: The Bcl-2 family: regulators of the cellular life-of-death switch. Nat Rev Cancer 2: 647-656, 2002.

3. Reed JC: Mechanisms of apoptosis. Am J Pathol 157: 1415-1430, 2000.

4. Gross A, McDonnell JM and Korsmeyer SJ: BCL-2 family members and the mitochondria in apoptosis. Genes Dev 13: $1899-1911,1999$.

5. Vaux DL and Korsmeyer SJ: Cell death in development. Cell 96: 245-254, 1999

6. Hsu YT, Wolter KG and Youle RJ: Cytosol-to-membrane redistribution of Bax and Bcl- $\mathrm{X}_{\mathrm{L}}$ during apoptosis. Proc Natl Acad Sci USA 94: 3668-3672, 1997.

7. Wolter KG, Hsu YT, Smith CL, Nechushtan A, Xi XG and Youle RJ: Movement of Bax from the cytosol to mitochondria during apoptosis. J Cell Biol 139: 1281-1292, 1997.

8. Antonsson B, Montessuit S, Lauper S, Eskes R and Martinou JC: Bax oligomerization is required for channel-forming activity in liposomes and to trigger cytochrome $c$ release from mitochondria. Biochem J 345: 271-278, 2000.
9. Jürgensmeier JM, Xie Z, Deveraux Q, Ellerby L, Bredesen D and Reed JC: Bax directly induces release of cytochrome $c$ from isolated mitochondria. Proc Natl Acad Sci USA 95: 4997-5002, 1998.

10. Kluck RM, Bossy-Wetzel E, Green DR and Newmeyer DD: The release of cytochrome $c$ from mitochondria: a primary site for Bcl-2 regulation of apoptosis. Science 275: 1132-1136, 1997.

11. Yang J, Liu X, Bhalla K, Kim CN, Ibrado AM, Cai J, Peng TI Jones DP and Wang X: Prevention of apoptosis by Bcl-2: release of cytochrome $c$ from mitochondria blocked. Science 275: 1129-1132, 1997.

12. Thomenius MJ, Wang NS, Reineks EZ, Wang $Z$ and Distelhorst $\mathrm{CW}$ : Bcl-2 on the endoplasmic reticulum regulates Bax activity by binding to BH3-only proteins. J Biol Chem 278: 6243-6250, 2003.

13. Antonsson B, Conti F, Ciavatta A, Montessuit S, Lewis S, Martinou I, Bernasconi L, Bernard A, Mermod JJ, Mazzei G, Maundrell K, Gambale F, Sadoul R and Martinou JC: Inhibition of Bax channel-forming activity by Bcl-2. Science 277: 370-372, 1997.

14. Youle RJ and Strasser A: The BCL-2 protein family: opposing activities that mediate cell death. Nat Rev Mol Cell Biol 9: 47-59, 2008.

15. Yip KW and Reed JC: Bcl-2 family proteins and cancer. Oncogene 27: 6398-6406, 2008.

16. Kitada S,Pedersen IM,Schimmer AD and Reed JC: Dysregulation of apoptosis genes in hematopoietic malignancies. Oncogene 21: 3459-3474, 2002.

17. Newman DJ, Cragg GM and Snader KM: The influence of natural products upon drug discovery. Nat Prod Rep 17: 215-234, 2000.

18. Gordaliza M: Natural products as leads to anticancer drugs. Clin Transl Oncol 9: 767-776, 2007.

19. Ju HK, Baek SH, An RB, Bae K, Son KH, Kim HP, Kang SS, Lee SH, Son JK and Chang HW: Inhibitory effects of nardostachin on nitric oxide, prostaglandin $E_{2}$, and tumor necrosis factor- $\alpha$ production in lipopolysaccharide activated macrophages. Biol Pharm Bull 26: 1375-1378, 2003.

20. Chiu LC, Ho TS, Wong EY and Ooi VE: Ethyl acetate extract of Patrinia scabiosaefolia downregulates anti-apoptotic $\mathrm{Bcl}-2 / \mathrm{Bcl}-\mathrm{X}_{\mathrm{L}}$ expression, and induces apoptosis in human breast carcinoma MCF-7 cells independent of caspase-9 activation. J Ethnopharmacol 105: 263-268, 2006.

21. Peng J, Chen YQ, Lin JM, Zhuang ZQ, Xu W, Hong ZF and Sferra TJ: Patrinia scabiosaefolia extract suppresses proliferation and promotes apoptosis by inhibiting STAT3 pathway in human multiple myeloma cells. Mol Med Rep 4: 313-318, 2011.

22. Jemal A, Bray F, Center MM, Ferlay J Ward E and Forman D: Global cancer statistics. CA Cancer J Clin 61: 69-90, 2011.

23. Gustin DM and Brenner DE: Chemoprevention of colon cancer: current status and future prospects. Cancer Metastasis Rev 21: 323-348, 2002.

24. Gorlick R and Bertino JR: Drug resistance in colon cancer. Semin Oncol 26: 606-611, 1999.

25. Longley DB, Allen WL and Johnston PG: Drug resistance, predictive markers and pharmacogenomics in colorectal cancer. Biochim Biophys Acta 1766: 184-196, 2006.

26. Boose G and Stopper H: Genotoxicity of several clinically used topoisomerase II inhibitors. Toxicol Lett 116: 7-16, 2000.

27. Mäntymaa P, Siitonen T, Guttorm T, Säily M, Kinnula V, Savolainen ER and Koistinen P: Induction of mitochondrial manganese superoxide dismutase confers resistance to apoptosis in acute myeloblastic leukaemia cells exposed to etoposide. Br J Haematol 108: 574-581, 2000.

28. Körper S, Nolte F, Rojewski MT, Thiel E and Schrezenmeier H: The $\mathrm{K}^{+}$channel openers diazoxide and NS1619 induce depolarization of mitochondria and have differential effects on cell $\mathrm{Ca}^{2+}$ in CD34+ cell line KG-1a. Exp Hematol 31: 815-823, 2003. 